\title{
Effect of Methanol Extract of Gomphrena celesioides on Chloroquine-Induced Hepatotoxicity and Oxidative Stress in Male Wistar Rats
}

\author{
Tijani S. Abiola ${ }^{*}$, Awaje Dorcas ${ }^{1}$, 0. O. Babalola ${ }^{2}$ \\ ${ }^{1}$ Department of Biochemistry, Bowen University, Iwo, Nigeria \\ ${ }^{2}$ Department of Biochemistry and Molecular Biology, Obafemi Awolowo University, Ile Ife, Nigeria \\ Email: ^tijaniabiol@yahoo.com,dorcasawaje@gmail.com, doctorbablo@yahoo.com
}

How to cite this paper: Abiola, T.S., Dorcas, S. and Babalola, O.O. (2019) Effect of Methanol Extract of Gomphrena celesioides on Chloroquine-Induced Hepatotoxicity and Oxidative Stress in Male Wistar Rats. American Journal of Molecular Biology, 9, 191-203.

https://doi.org/10.4236/ajmb.2019.94014

Received: April 24, 2019

Accepted: September 16, 2019

Published: September 19, 2019

Copyright $\odot 2019$ by author(s) and Scientific Research Publishing Inc. This work is licensed under the Creative Commons Attribution International License (CC BY 4.0).

http://creativecommons.org/licenses/by/4.0/

\begin{abstract}
Hepatic injury has been reported to be associated with chloroquine therapy. Gomphrena celesioides has been claimed to have pleiotropic protective properties in the liver by traditional herbal practitioner but there is no scientific evidence to this claim. This investigation therefore sought to evaluate the effect of Gomphrena celesioides administration on chloroquine-induced hepatic injury in rats. Forty adult male rats were divided into five groups of eight rats and were treated orally once daily. Rats in group one received 1 $\mathrm{ml} / \mathrm{kg}$ body weight of $0.9 \%$ normal saline; rats in group two received 250 $\mathrm{mg} / \mathrm{kg}$ body weight of chloroquine for three days; groups three, four and five rats were pre-treated with $200 \mathrm{mg} / \mathrm{kg}, 400 \mathrm{mg} / \mathrm{kg}$ and $800 \mathrm{mg} / \mathrm{kg}$ body weight of methanol extract of Gomphrena celesiodes for three days and on the fourth day were given $250 \mathrm{mg} / \mathrm{kg}$ body weight of chloroquine for three days. The experiment lasted for seven days. Liver injury was manifested biochemically by a significant increase in serum level or activities of hepatic markers (aminotransferases, alkaline phosphate, bilirubin, cholesterol and gamma glutamyl transferase). In addition, hepatic tissue from chloroquine-treated rats showed a significant increase in lipid peroxidation with a decrease in hepatic superoxide dismutase, catalase, glutathione peroxidase, glutathione-S-transferase and glutathione reservoirs. Moreover, the liver histopathologic evaluation revealed significant in chloroquine-treated rats. Gomphrena celesioides administration significantly alleviated chloroquine-induced pathologic changes in serum biochemistry and liver tissue. The results also suggest that Gomphrena celesioides possesses protective properties against chloroquine-induced liver injury via mitigation of drug-induced oxidative stress and its consequent events.
\end{abstract}




\section{Keywords}

Hepatic, Oxidative Stress, Gomphrena celesioides, Lipid Peroxidation

\section{Introduction}

Liver is a vital organ of the body and plays a crucial role in regulating the various physiological processes of human body and plays a magnificent role in the metabolism of endogenous and exogenous agents including detoxification and removal of toxic wastes from the body [1]. It has a great capacity to detoxify toxic substances and synthesize useful metabolites. Humans are exposed intentionally and unintentionally to a variety of diverse chemical agents that harm target organs of the body including the liver. Indiscriminate use of certain therapeutic drugs such as paracetamol, anti-malarial drugs, anti-tubercular drugs, oral contraceptives, analgesics, antidepressants, anti-arrhythmic drugs and toxic substance (carbon tetrachloride $\left[\mathrm{CCl}_{4}\right]$, thioacetamide, aflatoxin), etc. are threat to the integrity of the liver. Uncontrolled consumption of alcohol, various infections and some autoimmune disorders can also facilitate hepatic damage [2]. These hepatotoxic agents are one of the leading causes for hepatitis, cirrhosis, liver cancer and at last death [3]. Injury to the liver poses serious medical problems, which must be properly managed. Some of the liver injuries are caused by the use and abuse of drugs. Prescription-drugs like chloroquine can cause serious side effects especially when used in excess and for prolonged periods of time [4].

Numerous mechanisms of drug-induced liver injury have been identified, among which metabolism-mediated toxicity is well recognized. Although some parent compounds directly damage specific organelles such as mitochondria, reactive electrophilic metabolites and free radicals generated via hepatic drug metabolizing enzymes often produce toxicity. The toxic metabolites covalently bind to proteins, lipids, and DNA and cause adverse consequences such as oxidative stress, lipid peroxidation, DNA damage, glutathione depletion, and eventually cell death [5]. Toxic metabolites also provoke immune responses and sensitize the liver to toxicity [6]. Recently, mitochondrial dysfunction has emerged as one of the important underlying mechanisms in drug-induced liver injury, because several lines of evidence have revealed that mitochondria are the target of some drugs [7] [8].

Chloroquine is a member of an important series of chemically related antimalarial agents (the quinolone derivatives). Being a 4-aminoquinoline, it is a rapidly acting blood schizontocide with some gametocytocidal activity [9]. Chloroquine is effective for the treatment and prophylaxis of malaria [10] and has been the anti-malarial drug of choice for many years in most parts of the world, including Nigeria in spite of increasing prevalence of resistance of the malaria parasite to the drug [11]. However, evidences abound that over dosage and prolonged use of chloroquine are known to cause hepatotoxicity [12]. Chloroquine is also 
used in the management of lupus erythematosus and rheumatoid arthritis [13] [14]. Chloroquine is also one of the most effective disease-modifying antirheumatic drugs (DMARDs) [13]. Several cases of chloroquine-induced liver injury are reported [15] [16] and investigations have indicated the role of reactive metabolites and oxidative stress as one of the major mechanisms in chloroquine hepatotoxicity [11] [12].

Against the backdrop, that liver diseases are major global concerns and still have an extremely poor prognosis and high mortality, natural remedies from traditional plants are been sought for as safe and effective alternative treatments for hepatotoxicity. Many research efforts are now been directed towards the discovery and development of agents of plant origin, which might protect cells from oxidative reactions with potential hepatoprotective effects [4]. This study, therefore sought to evaluate the hepatoprotective potential of Gomphrena celesioides on chloroquine-induced liver damage.

\section{Materials and Methods}

\subsection{Chemicals}

Ellman's Reagent [5'-5'-dithiobis-(2-dinitrobenzoic acid), DNTB], sulphosalicylic acid, epinephrine, Folin-Ciocalteau reagent, Bovine serum albumin (BSA), trichloroacetic acid (TCA), thiobarbituric acid (TBA), reduced glutathione,1-chloro-2, 4-dinitrobenzene were supplied by Sigma-Aldrich ${ }^{\circledR}$ (USA), alanine aminotransferase (ALT) kit, aspartate aminotransferase (AST) kit, alkaline phosphates (ALP) kit, bilirubin kit, cholesterol kit, gamma glutaryl tranferase kit were from Randox Laboratories Limited, UK. All other chemicals and solvents are of analytical grade.

\subsection{Drug}

Chloroquine (250 mg) (Emzor Pharmaceutical Industries Ltd., Lagos, Nigeria) was purchased from the Pharmacy unit of Bowen University Teaching Hospital (BUTH), Iwo, Osun State. The tablets were dissolved in appropriate volume of sterile distilled water according to the required concentrations needed for administration to the rats on the basis of their body weight.

\subsection{Plant Materials}

Fresh leaves of Gomphrena celesioides (G. celesiodes) were collected in June 2018, from Bowen University, Iwo, Osun State, Nigeria. Iwo is located on latitude $7.6292^{\circ} \mathrm{N}$ and longitude $4.1872^{\circ} \mathrm{E}$. The plant material was identified and authenticated at Bowen University herbarium by Dr. Ayanbamiji, Department of Biological Sciences, Bowen University, Iwo, Osun State, Nigeria. The specimens sample was deposited with voucher number BUH 097.

\subsection{Preparation of the Extract}

The leaves of G. celesioides plant were harvested and air-dried for 7 days. The dried leaves were pulverized with an Electric Pulveriser (DIK-2910, Daiki Rika Kogyo 
Co. Ltd, Tokyo, Japan) and thereafter, $500 \mathrm{~g}$ of the powdered plant was weighed into a round bottomed flask and soaked in 5 litres of absolute methanol for 72 hours with intermittent shaking for complete extraction at room temperature. The mixture was filtered through a double layer cheese-cloth. The filtrate was concentrated in vacuo to dryness on Vacuum Pump Rotatory Evaporator (Edward Vacuum Co-operation, Crawley, England) at $40^{\circ} \mathrm{C}$ to give dark brown crude methanol extract. The crude methanol extract was stored in the desiccators until dryness. The dried crude extract which will be referred to as MEGC in this study was then stored and used for this study. The percentage (\%) yield of the extract was calculated.

\subsection{Experimental Animal and Design}

This study was carried out in compliance with national and international laws and Guidelines for Care and Use of Laboratory Animals in Biomedical Research Institutes of Health (revised 1985). Forty adult male Wistar rats weighing $150-200 \pm 2 \mathrm{~g}$ were obtained from the animal house of the Department of Physiology, University of Ibadan, and housed in the Animal House of the Department of Biochemistry, Bowen University, Iwo, Nigeria. The rats were acclimatized for two weeks and were kept in wire meshed cages at ambient temperature of $25^{\circ} \mathrm{C} \pm 3{ }^{\circ} \mathrm{C}$, fed with commercial rat pellets, had access to water ad libitum, and exposed to a natural daily photoperiod of about 12 hours light and 12 hours darkness during the period of acclimatization and throughout the study. After the acclimatization period, the rats were fasted for 24 hours before administration of the extract or chloroquine.

The study contained five experimental groups with eight rats per group and treated oral gavage; group one served as the normal control group and received 1 $\mathrm{ml} / \mathrm{kg}$ body weight of $0.9 \%$ normal saline, rats in group two received $250 \mathrm{mg} / \mathrm{kg}$ body weight of chloroquine (CQ) for three days, groups three, four and five rats were pre-treated with $200 \mathrm{mg} / \mathrm{kg}, 400 \mathrm{mg} / \mathrm{kg}$ and $800 \mathrm{mg} / \mathrm{kg}$ body weight of methanol extract of Gomphrena celesiodes for three days and on the fourth day were given $250 \mathrm{mg} / \mathrm{kg}$ body weight of chloroquine for three days. The experiment lasted for seven days. On the eight day, all the rats were humane sacrificed and blood was collected separately from each rat by retro-orbital bleeding, dispensed into anti-coagulant free bottle and allow clotting at room temperature $\left(28{ }^{\circ} \mathrm{C}\right)$ then centrifuged at $3000 \mathrm{~g}$ for ten minutes to obtain serum. The serum obtained was stored at $-20^{\circ} \mathrm{C}$ and used for evaluation of hepatotoxicity parameters. The liver from each rat was also collected into separate tube, rinsed with ice-cold saline, blotted and weighed then homogenized with ice-cold $0.1 \mathrm{M}$ Tris- $\mathrm{HCl}$ buffer ( $\mathrm{pH}$ 7.4) using ultra homogenizer. The homogenate was centrifuged at 10,000 $\mathrm{g}$ for fifteen minutes. The supernatant were collected into separate tubes, stored at $-20^{\circ} \mathrm{C}$ and used for the antioxidant assays.

\subsection{Evaluation of Hepatotoxicity Parameters}

The serum levels of alanine aminotransferase (ALT), aspartate aminotransferase 
(AST) and alkaline phosphatase (ALP), bilirubin (BIL), cholesterol, gamma glutamyl transferase (GGT) were evaluated spectrophotometrically by an Ultrospec2000 ${ }^{\circledR}$ spectrophotometer (Pharmacia Biotech, Uppsala, Sweden) in accordance with the methods provided by the diagnostic kits (Randox Laboratories Limited, UK).

\subsection{Antioxidant Assays}

Assessment of liver antioxidant statues was evaluated by determining the activities of superoxide dismutase (SOD) by Mirsa and Fridovich [17] method, catalase (CAT) by Sinha [18] method, method of Rotruck et al. [19] for glutathione peroxidase (GPx), glutathione-S-transferase (GST) by method of Habig et al. [20], whereas the levels of glutathione (GSH) was by the method of Buetler et al. [21], lipid peroxidation as expressed in terms of malondialdehyde (MDA) by the method of Varshney and Kale [22] and total protein concentration by Lowry et al. [23] method.

\subsection{Histological Assessment}

Sections of liver tissues were collected and fixed in 10\% formalin after sacrifice and each sample was embedded in paraffin and cut into $5 \mu \mathrm{m}$ thick slices using a Leica RM2135 microtome (Leica, Berlin, Germany), for histological evaluation. Tissue sections were stained with hematoxylin and eosin (H\&E) and examined under a light microscope (Leica Microsystems, Germany) as described by [24].

\subsection{Statistical Analysis}

All results were expressed as the Means of eight rats \pm S.E. using One way analysis of variance (ANOVA) and Duncan's multiple comparisons Test using Statistical packages for social Scientists-version 18.0 (SPSS version 18.0). Value of $\mathrm{p}$ $<0.05$ was considered significant.

\section{Results}

Results of this study showed that administration of chloroquine at a dose of 250 $\mathrm{mg} / \mathrm{kg}$ body weight to Wistar rats caused a significant increase in the activities of all the hepatic enzymes estimated as well as the concentrations of both total and direct bilirubin and the cholesterol in the serum when compared with the normal control rats. However, pre-treatments with $200 \mathrm{mg} / \mathrm{kg}, 400 \mathrm{mg} / \mathrm{kg}$ and 800 $\mathrm{mg} / \mathrm{kg}$ body weight of MEGC for three days significantly decreased the activities of the enzymes and the concentrations of both bilirubin and cholesterol in a dose dependent manner Table 1.

As shown in Figure 1 \& Figure 2, the activities of both enzymatic and nonenzymatic antioxidant were significantly decreased in the liver homogenate with concomitant increase in the level of lipid peroxidation of the chloroquine alone treated group. Again pre-treatments with different doses of MEGC for three days brought the activities and levels of the antioxidant markers near to normal. 
Table 1. Activities of hepatic enzymes and concentrations of bilirubin and cholesterol of chloroquine-, MEGC-administered and control rats.

\begin{tabular}{|c|c|c|c|c|c|}
\hline & Control & CQ & MEGC1 +CQ & MEGC2 +CQ & MEGC3 + CQ \\
\hline ALT (IU/L) & $11.33 \pm 1.15$ & $53.50 \pm 0.71$ & $25.00 \pm 0.10^{*}$ & $16.01 \pm 0.20^{\# *}$ & $12.50 \pm 0.71^{\$ \#^{*}}$ \\
\hline AST (IU/L) & $10.75 \pm 0.50$ & $46.50 \pm 0.71$ & $27.00 \pm 0.20^{*}$ & $19.50 \pm 0.71^{\#^{*}}$ & $11.04 \pm 1.00^{\$ \#^{*}}$ \\
\hline ALP (IU/L) & $35.19 \pm 0.50$ & $88.32 \pm 0.10$ & $42.44 \pm 0.10^{*}$ & $37.32 \pm 1.59^{*^{*}}$ & $34.50 \pm 0.59^{\$ \#^{*}}$ \\
\hline $\mathrm{tBIL}(\mu \mathrm{mol} / \mathrm{L})$ & $6.64 \pm 0.13$ & $15.24 \pm 0.16$ & $11.43 \pm 0.21^{*}$ & $9.54 \pm 0.24^{\# *}$ & $6.69 \pm 0.24^{\$ *^{*}}$ \\
\hline $\mathrm{dBIL}(\mu \mathrm{mol} / \mathrm{L})$ & $3.64 \pm 0.30$ & $12.42 \pm 0.32$ & $8.98 \pm 0.58^{*}$ & $6.10 \pm 0.77^{\# *}$ & $2.98 \pm 0.98^{\mathrm{s**}}$ \\
\hline $\mathrm{CHOL}(\mu \mathrm{mol} / \mathrm{L})$ & $1.48 \pm 0.25$ & $5.10 \pm 0.65$ & $2.74 \pm 0.32^{*}$ & $1.66 \pm 0.22^{* *}$ & $1.42 \pm 0.19^{\$ *^{*}}$ \\
\hline GGT (IU/L) & $28.00 \pm 0.71$ & $56.00 \pm 0.26$ & $43.00 \pm 0.38^{*}$ & $32.00 \pm 0.17^{*^{*}}$ & $29.67 \pm 0.08^{\$ \#^{*}}$ \\
\hline
\end{tabular}

Results are expressed as mean \pm standard error of mean. ${ }^{*} \mathrm{p}<0.05$ is significant when compared with the chloroquine alone group. ${ }^{*} \mathrm{p}<0.05$ is significant when compared with the MEGC1 + CQ group. ${ }^{s} \mathrm{p}<0.05$ is significant when compared with the MEGC2 + CQ group. ALT: alanine aminotransferase; AST: aspartate aminotransferase; ALP: alkaline phosphatase; tBIL: total bilirubin; dBIL: direct bilirubin; CHOL: cholesterol; GGT: gamma-gutamyl transferase; MEGC1: $200 \mathrm{mg} / \mathrm{kg}$ body weight of methanol extract of Gomphrena.
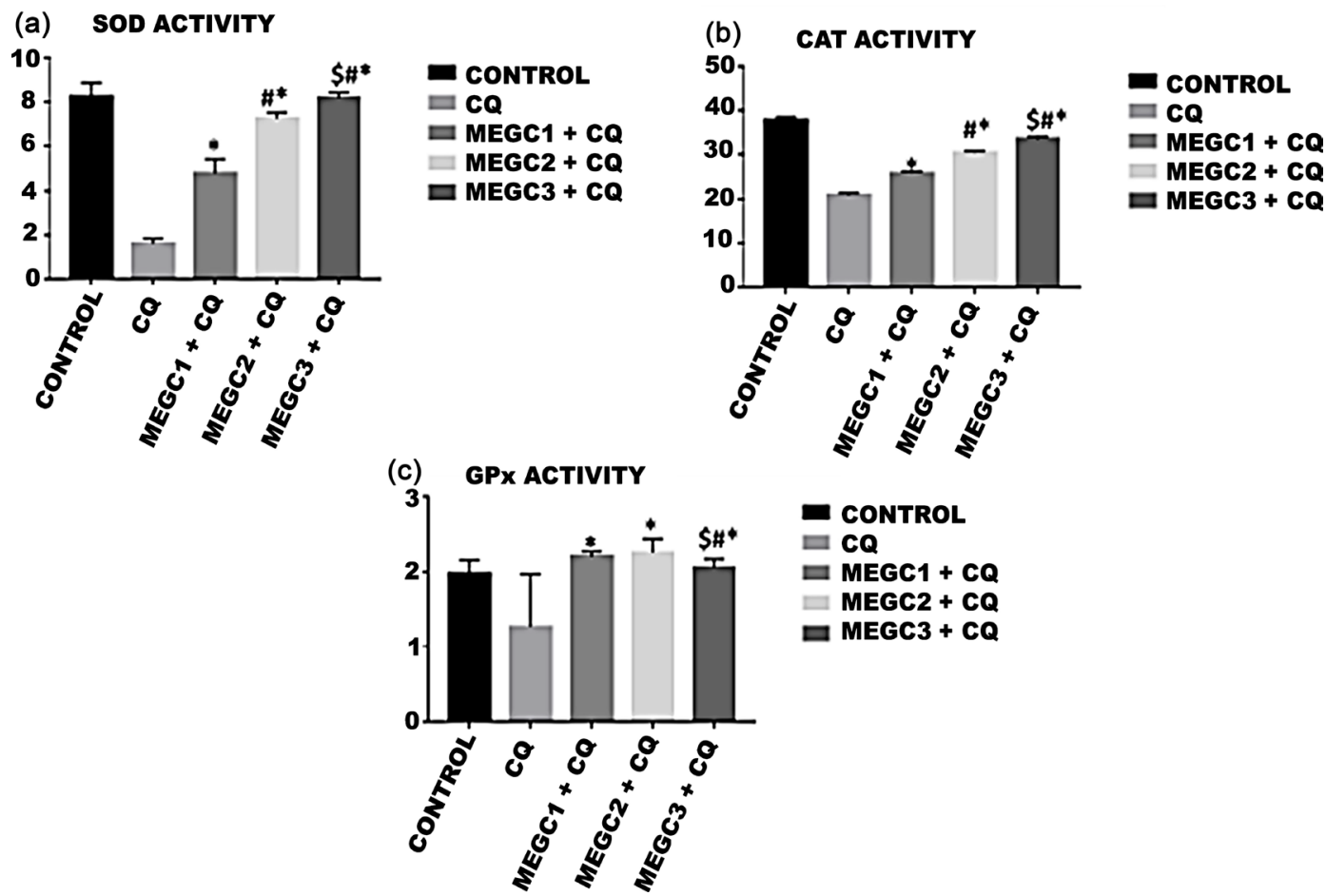

Figure 1. Activities of antioxidant enzymes of chloroquine-, MEGC-administered and control rats. Each bar represents mean \pm standard error of mean. ${ }^{*} p<0.05$ is significant when compared with the chloroquine alone group. ${ }^{*} p<0.05$ is significant when compared with the MEGC1 + CQ group. ${ }^{\$} p<0.05$ is significant when compared with the MEGC2 + CQ group. SOD: superoxide dismutase; CAT: catalase; Gpx: glutathione peroxidase.

\section{Discussion}

Currently, liver diseases have become a global health problem, lacking helpful curative approach. There are so many plants that are used as hepatoprotective agents in traditional medicine systems [3] [25]. It is, therefore, necessary to assess the 


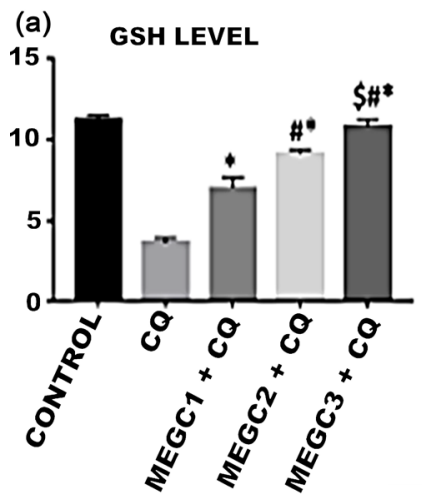

(b) GST ACTIVITY

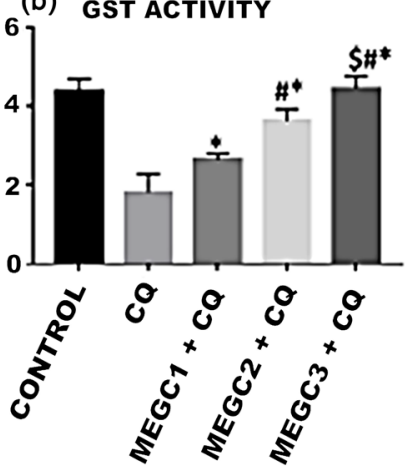

CONTROL 口CQ

曰 MEGC1 + CQ

MEGC2 + CQ

口 MEGC3 + CQ (c) LPO LEVEL

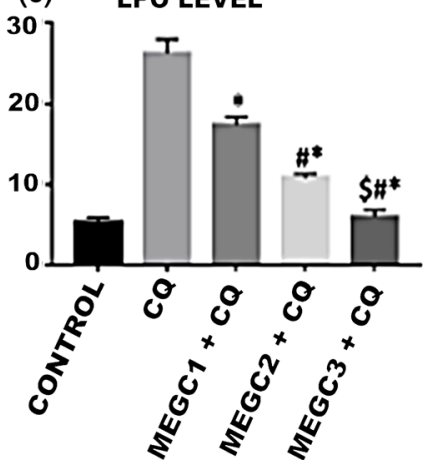

CONTROL $\square \mathbf{C Q}$ $\square$ MEGC1 + CQ $\square \mathrm{MEGC2}+\mathrm{CQ}$ $\square \mathrm{MEGC3}+\mathrm{CQ}$

Figure 2. Activity of GST and the levels of GSH and LPO of chloroquine-, MEGC-administered and control rats. Each bar represents mean \pm standard error of mean. ${ }^{*} p<0.05$ is significant when compared with the chloroquine alone group. ${ }^{*} p<0.05$ is significant when compared with the MEGC1 + CQ group. ${ }^{\$} p<0.05$ is significant when compared with the MEGC2 + CQ group. GST: glutathione-S-transferase; GSH: glutathione; LPO: lipid peroxidation.

scientific basis for the reported hepatoprotective activity of these plants. The current investigation was sought to evaluate the potential protective effects of MEGC against liver-induced damage.

Plasma concentration of liver enzymes is normally low, but is elevated in the event of hepatotoxicity, which may occur in alcohol, drug or herb induced liver damage leading to necrosis of hepatocytes, increased permeability and leakage of cellular enzymes from the liver cytosol into the blood stream. The main value of the aminotransferases, alkaline phosphatase, gamma glutamyl transferase, concentrations of bilirubin and cholesterol are usually use in detecting hepatocellular damage and monitoring the patient's progress as the levels rapidly return to normal following resolution of the factors causing hepatocellular damage. The observed increased in enzyme activities in the chloroquine group is thought to be due to a leakage of cytoplasmic enzyme into circulation as a result of hepatocytes damage.

The increased level of serum ALT and AST activities in chloroquine alone treated rats reflect damage to hepatocyte and indicated the increased cellular permeability [26] [27]. Pretreatment of the rats with different concentrations of the MEGC shows hepatoprotective effect of the extract on ALT and AST activities in the liver. The result of this present investigation agreed with the work of [28]. 
Serum bilirubin is usually used as a biomarker of biliary tree injury [29] [30]. The increased concentration of total and direct bilirubin with concomitant increase in the concentration of cholesterol and ALP activity in rats treated with chloroquine alone in the current investigation, revealed that the nature of the antimalarial drugs-induced hepatotoxicity is predominantly of the hepatocellular and cholestatic damage [29] [30]. Cholestasis may also be a consequence of the canalicular secretion of reactive metabolites or disintegration of labile glutathione and/or glucuronide conjugates thereby damaging cholangiocytes or triggering an immune response. Increased level of GGT in the chloroquine alone treated group also confirm the hepatocyte membrane damage and affirmed that the hepatocyte damage caused by chloroquine administration is hepatobiliary and cholestatic in nature [31] [32]. Administration of different doses of MECG however, restored the activities of these enzymes and the concentrations of bilirubin and cholesterol in rats.

Chloroquine is metabolized in liver through CYP2C8 and CYP3A4 [33]. It has been found that chloroquine-induced hepatotoxicity is associated with reactive oxygen species formation and oxidative stress in liver [11] [12]. ROS generation is a normal component of oxidative phosphorylation and plays a role in normal redox control of physiological signalling pathways [34] [35] [36]. However, excessive ROS generation triggers cell dysfunction, lipid peroxidation, and DNA mutagenesis and can lead to irreversible cell damage or death [34] [35] [36] and other ROS-mediated alterations in the cell. Modification of proteins by ROS can cause inactivation of critical enzymes and can induce denaturation that renders proteins non-functional [37] [38]. Several lines of evidence suggest that the formation of reactive metabolites play a central role in the pathogenesis of drug-liver injury [39]. Reactive metabolites can covalently bind proteins to form drug-protein adducts that might trigger immune-mediated reactions or exert direct toxicity [40] [41]. Oxidative damage in the liver could be a consequence of cytosolic oxidant stress after drug metabolism or could arise from oxidant stress directly generated in mitochondria and the subsequent inflammatory cell response by injured hepatocytes.

In this present study, chloroquine markedly decreased the activities of SOD, CAT, GPx and GST a phase II drug-metabolizing enzyme. This result is in agreement with the work of [42]. Farombi and Emerole [43] reported that chloroquine increased the cholesterol/phospholipid ratio, thereby disrupting membrane fluidity and leading to membrane alteration of function. In agreement with this, in our study also the levels of lipids increased in chloroquine treated rats suggesting that chloroquine has devastating effect on membrane stability and functional state. The enzymatic antioxidant defence systems are the nature protector against lipid peroxidation. SOD, CAT and GPx enzymes are important scavengers of superoxide ion and hydrogen peroxide. These enzymes prevent generation of hydroxyl radical and protect the cellular constituents from oxidative damage [44]. The decreased activities of SOD, CAT, GPx and GST observed 
in the chloroquine administered rats suggesting the increased lipid peroxidation. Administration of MEGC in different doses to rats increased the activities of SOD, CAT, GPx and GST, this may result from the scavenging of the radicals generated by chloroquine-induced lipid peroxidation, and thereby decreasing the utilization of these antioxidant enzymes to reduce the chloroquine-induced oxidative threat.

Increased ROS level affect some potential targets in cells including membrane lipids and cellular proteins [45]. Cellular glutathione (GSH) depletion is also a common event after oxidative stress [46]. Glutathione has an important role in hepatocyte defence against toxicity [46]. Severe glutathione depletion leaves the liver vulnerable to oxidative damage which causes progressive deterioration of macromolecules and finally organ injury. The result of this study revealed a significant depletion of the GSH level in the chloroquine alone treated group. This result is in agreement with the report of [47]. However, pretreated with varying doses of MEGC raised the GSH level in rats.

The histopathological assessments of rats treated with chloroquine alone showed feathery degeneration and/microvesicular type of fatty generation with sinusoidal dilation and focal necrosis. These observations were however very much ameliorated histopathologically in rats treated with chloroquine and MEGC (Figure 3).

Overall, we found that treatment with MEGC protects the liver through attenuation of lipid peroxidation and decreased the production of free radical derivatives, as evident from the decreased levels of liver TBARS (lipid peroxidation),
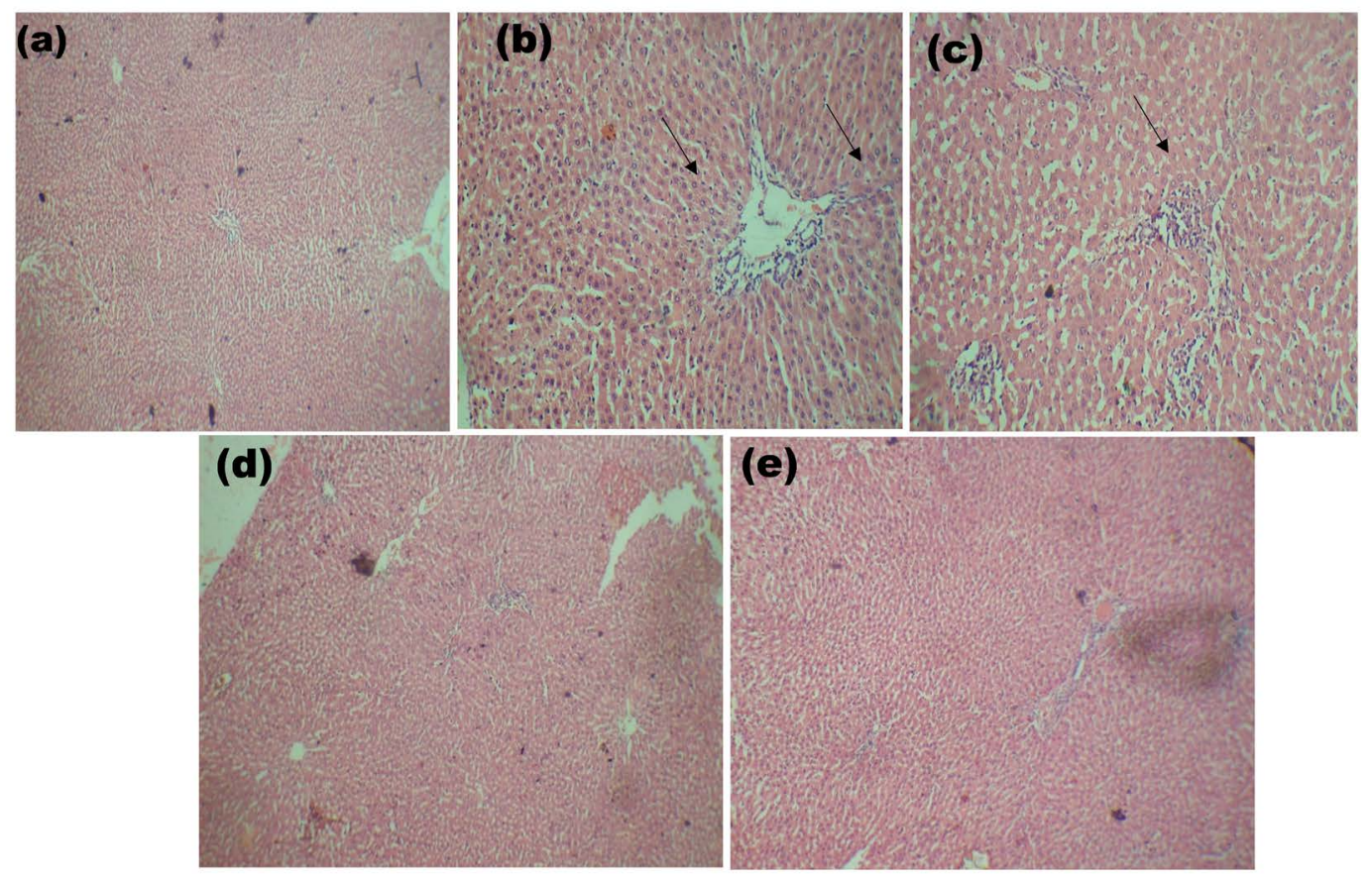

Figure 3. Photomicrograph of liver sections from (a) Normal control group with normal hepatocyte architecture; (b) CQ treated with sinusoidal congestion, hepatocyte vacuolization, inflammation and focal necrosis; (c) $200+$ CQ with inflammation and mild focal necrosis; (d) 400+ CQ normal hepatocyte with mild inflammation; (e) $800+$ CQ hepatocytes appear normal. (H \& E, ×40). 
ROS formation and restoration of the architectural structure of the liver as observed in the histological assessment. As reported in the in-vitro study, MEGC possesses free radicals scavenging and activity and antioxidant properties. Hence, the antioxidant capacity of MEGC along with its ability to protect intracellular targets such as different proteins might be involved in its mechanism of hepatoprotection against chloroquine-induced damage.

\section{Conclusion}

In conclusion, this present investigation indicates that MECG exerts protection against chloroquine-induced liver toxicity possibly through mitigation of druginduced oxidative stress and its consequent events. The results of this study suggest that MECG could be administered as an adjuvant therapy with chloroquine to reduce the adverse effects on the liver. Furthermore, MECG might be considered as a therapeutic option for a range of drugs and other xenobiotics-induced oxidative stress and liver injury.

\section{Conflicts of Interest}

The authors declare no conflicts of interest regarding the publication of this paper.

\section{References}

[1] Chaturvedi, R., George, S. and John, A. (2007) Preventive and Protective Effect of Wild Basil in Ethanol-Induced Liver Toxicity in Rats. British Journal of Biomedical Science, 64, 10-12. https://doi.org/10.1080/09674845.2007.11732748

[2] Singh, A., Bhat, T.K. and Sharma, O.P. (2011) Clinical Biochemistry of Hepatotoxicity. Journal of Clinical Toxicology, S4, 001.

[3] Pandit, A., Sachdeva, T. and Bafna, P. (2012) Drug-Induced Hepatotoxicity: A Review. Journal of Applied Pharmacological Science, 2, 233-243. https://doi.org/10.7324/JAPS.2012.2541

[4] Nnodim, J., Uduji, H.I. and Udujih, G.O. (2014) The Role of Gangronema latifolium Attenuation of Chloroquine Induced Nephrotoxicity and Hepatotoxicity. Asian Pacific Journal of Nursing, 1, 20-23.

[5] Jaeschke, H. (2011) Reactive Oxygen and Mechanisms of Inflammatory Liver Injury. Present Concepts. Journal of Gastroenterology and Hepatology, 26, 173-179. https://doi.org/10.1111/j.1440-1746.2010.06592.x

[6] Gunawan, B.K. and Kaplowitz, N. (2007) Mechanisms of Drug-Induced Liver Disease. Clinical Liver Diseases, 11, 459-475. https://doi.org/10.1016/j.cld.2007.06.001

[7] Nadanaciva, S. and Will, Y. (2009) The Role of Mitochondrial Dysfunction and Drug Safety. IDrugs, 12, 706-710.

[8] Russmann, S., Kullak-Ublick, G.A. and Grattagliano, I. (2009) Current Concepts of Mechanisms in Drug-Induced Hepatotoxicity. Current Medicinal Chemistry, 16, 3041-3053. https://doi.org/10.2174/092986709788803097

[9] Ekanem, D.J., Weisfeld, C. and Salako, L.A. (1990) Sensitivity of Plasmodium falciparum to Chloroquine and Sulphadoxine in Nigerian Children. Bulletin of the World Health Organization, 68, 45-52. 
[10] Lalloo, D.G., Shingadia, D., Pasvol, G., Chiodinid, P.L., Whitty, C.J., Beeching, N.J., et al. (2007) UK Malaria Treatment Guidelines. Journal of Infection, 54, 111-121. https://doi.org/10.1016/j.jinf.2006.12.003

[11] Pari, L. and Amali, D.R. (2005) Protective Role of Tetrahydrocurcumin (THC) an Active Principle of Turmeric on Chloroquine-Induced Hepatotoxicity in Rats. Journal of Pharmacology and Pharmaceutical Science, 8, 115-23.

[12] Kumar Mishra, S., Singh, P. and Rath, S.K. (2013) Protective Effect of Quercetin on Chloroquine-Induced Oxidative Stress and Hepatotoxicity in Mice. Malaria Research Treatment, 2013, Article ID: 141734. https://doi.org/10.1155/2013/141734

[13] Smolen, J.S., Landewé, R., Breedveld, F.C., Maya, B., Burmester, G., Dougados, M., et al. (2014) EULAR Recommendations for the Management of Rheumatoid Arthritis with Synthetic and Biological Disease-Modifying Anti-Rheumatic Drugs: 2013 Update. Annals of the Rheumatic Diseases, 73, 492-509. https://doi.org/10.1136/annrheumdis-2013-204573

[14] Rainsford, K.D., Parke, A.L., Clifford-Rashottem, M. and Kean, W.F. (2015) Therapy and Pharmacological Properties of Hydroxychloroquine and Chloroquine in Treatment of Systemic Lupus Erythematosus, Rheumatoid Arthritis and Related Diseases. Inflammopharmacology, 23, 231-269. https://doi.org/10.1007/s10787-015-0239-y

[15] Taylor, W.R.J. and White, N.J. (2004) Antimalarial Drug Toxicity. Drug Safety, 27, 25-61. https://doi.org/10.2165/00002018-200427010-00003

[16] AlKadi, H.O. (2007) Antimalarial Drug Toxicity: A Review. Chemotherapy, 53, 385-391. https://doi.org/10.1159/000109767

[17] Misra, H.P. and Fridovich, I. (1972) The Role of Superoxide Anion in the Auto Oxidation of Epinephrine and a Simple Assay of Superoxide Dismutase. Journal of Biological Chemistry, 247, 3170-3175.

[18] Sinha, A.K. (1972) Colorimetric Assay of Catalase. Analytical Biochemistry, 47, 389-394. https://doi.org/10.1016/0003-2697(72)90132-7

[19] Rotruck, J.T., Pope, A.L., Ganther, H.E., Swanson, A.B., Hafeman, D.G. and Hoekstra, W.G. (1973) Selenium: Biochemical Role as a Component of Glutathione Peroxidise. Science, 179, 588-590. https://doi.org/10.1126/science.179.4073.588

[20] Habig, W.H., Pabst, M.J. and Jacoby, W.B. (1974) Glutathione-S-Transferases. The First Enzymatic Step in Mercapturic Acid Formation. Journal of Biological Chemistry, 249, 7130-7139.

[21] Beutler, E., Duron, O. and Kelly, B.M. (1963) Improved Method for the Determination of Blood Glutathione. Journal of Laboratory Clinical Medicine, 61, 882-888.

[22] Varshney, R. and Kale, R.K. (1990) Effect of Calmodulin Antagonist on Radiation Induced Lipid Peroxidation in Microsomes. International Journal of Radical Biology, 58, 733-743. https://doi.org/10.1080/09553009014552121

[23] Lowry, O.H., Rosenbrough, N.M., Farr, A.L. and Randali, R.J. (1951) Protein Measurement with Folin Phenol Reagent. Journal of Biological Chemistry, 193, 265.

[24] Wu, R.E., Huang, W.C., Liao, C.C., Chang, Y.K., Kan, N.W. and Huang, C.C. (2013) Resveratrol Protects against Physical Fatigue and Improves Exercise Performance in Mice. Molecules, 18, 4689-4702. https://doi.org/10.3390/molecules 18044689

[25] Sridevi, V.K., Chouhan, H.S., Singh, N.K. and Singh, S.K. (2012) Antioxidant and Hepatoprotective Effects of Ethanol Extract of Vitex glabrata on Carbon Tetrachloride-Induced Liver Damage in Rats. Natural Product Research, 26, 1135-1140. https://doi.org/10.1080/14786419.2011.560849 
[26] Nitti, M., Pronzato, M.A., Marinari, U.M. and Domenicotti, C. (2008) PKC Signaling in Oxidative Hepatic Damage. Molecular Aspects of Medicine, 29, 36-42. https://doi.org/10.1016/j.mam.2007.09.001

[27] Ozer, J., Ratner, M., Shaw, M., Baily, W. and Schomaker, S. (2008) The Current Status of Serum Biomarkers of Hepatotoxicity. Toxicology, 244, 194-205. https://doi.org/10.1016/j.tox.2007.11.021

[28] Imo, C., Uhegbu, F.O., Ifeanacho, N.G. and Azubuike, N.C. (2015) Histological and Hepatoprotective Effect of Ethanolic Way Extract of Gongronema latifolium Berthin Acetaminophen-Induced Hepatic Toxicity in Male Albino Rats. International Journal of Preventive Medicine Research, 1, 217-226. https://doi.org/10.9734/ACSJ/2015/18881

[29] Hong, H. and Tong, W. (2014) Emerging Efforts for Discovering New Biomarkers of Liver Disease and Hepatotoxicity. Biomarker Medicine, 8, 143-146. https://doi.org/10.2217/bmm.13.156

[30] Heidari, R., Jamshidzadeh, A., Keshavarz, N.C. and Azarpira, N. (2015) Mitigation of Methimazole-Induced Hepatic Injury by Taurine in Mice. Science Pharmacology, 83, 143-158. https://doi.org/10.3797/scipharm.1408-04

[31] Sheehan, M. and Haythorn, P. (1979) Predictive Values of Various Liver Function Tests with Respect to the Diagnosis of Liver Disease. Clinical Biochemistry, 12, 262-263. https://doi.org/10.1016/S0009-9120(79)80122-8

[32] Leonard, T.B., Neptun, D.A. and Popp, J.A. (1984) Serum Gamma Glutamyl Transferase as a Specific Indicator of Bile Duct Lesions in the Rat Liver. American Journal of Pathology, 116, 262-269.

[33] Kim, K.A., Park, J.Y., Lee, J.S. and Lim, S. (2003) Cytochrome P450 2 C8 and CYP3A4/5 Are Involved in Chloroquine Metabolism in Human Liver Microsomes. Archives of Pharmacal Research, 26, 631-637. https://doi.org/10.1007/BF02976712

[34] Sawyer, D.B., Siwik, D.A., Xiao, L., Pimentel, D.R., Singh, K. and Colucci, W.S. (2002) Role of Oxidative Stress in Myocardial Hypertrophy and Failure. Journal of Molecular Cell Cardiology, 34, 379-388. https://doi.org/10.1006/jmcc.2002.1526

[35] Giordano, F.J. (2005) Oxygen, Oxidative Stress, Hypoxia, and Heart Failure. Journal of Clinical Investigation, 115, 500-508. https://doi.org/10.1172/JCI200524408

[36] Murdoch, C.E., Zhang, M., Cave, A.C. and Shah, A.M. (2006) NADPH Oxidase-Dependent Redox Signaling in Cardiac Hypertrophy, Remodelling and Failure. Cardiovascular Research, 71, 208-215. https://doi.org/10.1016/j.cardiores.2006.03.016

[37] Lockwood, T.D. (2000) Redox Control of Protein Degradation. Antioxidant Redox Signaling, 2, 851-878. https://doi.org/10.1089/ars.2000.2.4-851

[38] Stadtman, E.R. and Levine, R.L. (2003) Free Radical Mediated Oxidation of Free Amino Acids and Amino Acid Residues in Proteins. Amino Acids, 25, 207-218. https://doi.org/10.1007/s00726-003-0011-2

[39] Knowles, S.R., Uetrecht, J. and Shear, N.H. (2000) Idiosyncratic Drug Reactions: The Reactive Metabolite Syndromes. The Lancet, 356, 1587-1591. https://doi.org/10.1016/S0140-6736(00)03137-8

[40] Pessayre, D., Fromenty, B., Berson, A., Robin, M.A., Lettéron, P., Moreau, R., et al. (2012) Central Role of Mitochondria in Drug-Induced Liver Injury. Drug Metabolism Review, 44, 34-87. https://doi.org/10.3109/03602532.2011.604086

[41] Faulkner, L., Meng, X., Park, B.K. and Naisbitt, D.J. (2014) The Importance of Hapten-Protein Complex Formation in the Development of Drug Allergy. Current Opinion and Allergy Clinical Immunology, 14, 293-300. 
https://doi.org/10.1097/ACI.0000000000000078

[42] Jamshidzadeh, A., Heidari1, R., Abazari, F., Ramezani, M., Khodaei, F., Mehdi Ommati, M., et al. (2016) Antimalarial Drugs-Induced Hepatic Injury in Rats and the Protective Role of Carnosine. Journal of Pharmaceutical Sciences, 22, 170-180. https://doi.org/10.15171/PS.2016.27

[43] Farombi, E.O. and Emerole, G.O. (1998) Interference of Common Antimalarial Drugs with Some Hepatic Microsomal Components and Drug Metabolism: Potential Implication for Toxicity. South African Journal of Science, 94, 303-304.

[44] Scott, M.D., Lubin, B.H., Zuo, L. and Kuypers, F.A. (1991) Erythrocyte Defence against Hydrogen Peroxide: Preeminent Importance of Catalase. Journal of Laboratory and Clinical Medicine, 118, 7-16.

[45] Jaeschke, H., Gores, G.J., Cederbaum, A.I., Hinson, J.A., Pessayre, D. and Lemasters, J.J. (2002) Mechanisms of Hepatotoxicity. Toxicological Science, 65, 166-176. https://doi.org/10.1093/toxsci/65.2.166

[46] Reed, D.J. (1990) Glutathione: Toxicological Implications. Annual Review of Pharmacological Toxicology, 30, 603-631.

https://doi.org/10.1146/annurev.pa.30.040190.003131

[47] Winkler, B.S. (1992) Unequivocal Evidence Is Support of Non-Enzymatic Redox Coupling between Glutathione/Glutathione Disulphide and Ascorbic Acid, Dehydro-Ascorbic Acid. Biochimica et Biophysica Acta, 1117, 287-290. https://doi.org/10.1016/0304-4165(92)90026-Q 